\title{
CART - CREATIVE APPLICATION TO REMEDY TRAFFIC
}

\author{
R. KASPRZYK, K. SZKÓŁKA, T. POŁAWSKI, M. PYŻARNOWSKI, P. GIĘTKOWSKI \\ rkasprzyk@wat.edu.pl
}

Institute of Computer and Information Systems

Faculty of Cybernetics, Military University of Technology

Kaliskiego Str. 2, 00-908 Warsaw

\begin{abstract}
CART is a simulation software assisting decision-making process, aiming at enhancing the throughput of transport infrastructure and "fluidity" of vehicle traffic in urban agglomerations. Thanks to innovative solutions combining state-of-the-art software technologies with achievements in graph and network theories, the system is capable of improving present traffic conditions. The system is designated both for organisations responsible for management of urban traffic and for road users. The first group is able, in a conscious and effective way assess usability of the solution (layout of traffic lights, construction of gas stations/parking lots, modifying/extending the network of roads) to the town, by analysing results of simulations of modified road infrastructure. The second group, thanks to using the intelligent traffic management assistance system, will be able to drive throughout the town in a more fluid way.
\end{abstract}

Keywords: complex networks, centrality measures, roads infrastructure, optimization, simulation.

\section{Introduction}

The problem of traffic jams affects all cities around the globe. Increasing number of cars especially in vast agglomerations has a negative impact on city traffic. The road infrastructure in most cities is becoming insufficient and inefficient. That's the basis of traffic jams which are the reason for consuming larger portions of resources like time, gasoline, money and even sometimes human lives.

We often face a problem when roads are being closed or there was an accident so the road is blocked. Instantly traffic jam arises. Authorities are obliged to make a detour. The arrangement of the detour should be minimized so the drivers won't really feel there was a change. The goal is to create a detour without delay.

Major problem in big cities are bus lanes. Passengers state that there should be more of them so the buses would be privileged. Research showed that the idea is good but not always and not everywhere.

Businesses claim for the best places for their facilities. For a new business and existing ones, which want to branch out, is important to find appropriate place to build new petrol station, another mall or start with other facility.

Pollution and noise control concerns every city. The parties are obligated to minimize those factors. The question is how to build road infrastructure that will bring the lowest noise and pollution levels both for human and animals.

Last but not least, once drivers are already in traffic jams, they want to know which road to take, to avoid standing in them.

Mentioned objectives can be achieved and problems solved using Complex Networks theory together with the computer simulation. In particular, the proposed solution - CART (Creative Application to Remedy Traffics) - uses model of Complex Networks (e.g. Small World and Scale Free networks) and so called centrality measures (e.g. degree centrality, betweenness centrality, radius centrality, closeness centrality, eigenvector centrality). Thanks to the computer simulation which utilizes statistical data it becomes feasible to optimize the topology of the road infrastructure. In consequence, CART is capable of improving present traffic conditions as well as help business to make right decisions concerning the best places for different kind of facilities. This is unique feature among existing traffic management systems.

\section{Definitions and notations}

Let's define the network as follows [2], [6]: $\operatorname{Net}(t)=\left\langle G(t)=\langle V(t), E(t)\rangle,\left\{f_{i}(v, t)\right\}_{\substack{i \in 11 \ldots N F \\ v \in V(t)}},\left\{h_{j}(e, t)\right\}_{\substack{j \in[1 \ldots 1, N H\} \\ e \in E(t)}}\right\rangle$ where: 
$G(t)=\langle V(t), E(t)\rangle-$ simple dynamic graph (the dynamic means that $V(t)$ and $E(t)$ can change over time);

$V(t), E(t)$ - sets of graph's vertices and edges, $E(t) \subset\left\{\left\{v, v^{\prime}\right\}: v, v^{\prime} \in V(t)\right\} ; f_{i}: V(t) \rightarrow V a l_{i}$ - the i-th function describe on the graph's vertices, $i=1, . ., N F, \quad(N F-$ number of vertex's functions), $V a l_{i}$ - is a set of $f_{i}$ values; $h_{j}: E(t) \rightarrow V a l_{j}-$ the $j$-th function describe on the graph's edges, $j=1, . ., N H,(N H-$ number of edge's functions), $\mathrm{Val}_{j}-$ is a set of $h_{j}$ values.

We assume that values of function's $f_{i}(\cdot)$ and $h_{j}(\cdot)$ can also change over time.

Simple dynamic graphs are very often represented by a matrix $A(t)$ called adjacency matrix, which is a $|V(t)| \times|V(t)|$ symmetric matrix. The element $a_{i j}(t)$ of adjacency matrix equals 1 if there is an edge between vertices $i$ and $j$, and 0 otherwise.

The first-neighbourhood of a vertex $v_{i}$ denote as $\Gamma_{i}^{1}(t)$ is defined as set of vertices immediately connected with $v_{i}$, i.e.:

$$
\Gamma_{i}^{1}(t)=\left\{v_{j} \in V(t):\left\{v_{i}, v_{j}\right\} \in E(t)\right\}
$$

The degree $k_{i}(t)$ of a vertex $v_{i}$ is the number of vertices in the first-neighbourhood of a vertex $v_{i}$, i.e.:

$$
k_{i}(t)=\left|\Gamma_{i}^{1}(t)\right|
$$

The path starting in vertex $v_{0}$ and ending in vertex $v_{l}$ is a sequence of $\left\langle v_{0}, v_{1}, \ldots, v_{l}\right\rangle$ where $\left\{v_{i-1}, v_{i}\right\} \in E(t) \quad \forall i=1, \ldots, l$. The length of a path is defined as the number of links in it. The shortest path length starting in vertex $v_{i}$ and ending in vertex $v_{j}$ is denoted as $d_{i j}(t)$.

Now we can define diameter $D$ as the longest of the shortest paths i.e.:

$$
D(t)=\max _{v_{i}, v_{j} \in V(t)}\left\{d_{i j}(t)\right\}
$$

Let's denote the number of existing edges between the first-neighbourhood of a vertex $v_{i}$ as $N_{i}(t)$, i.e.:

$$
N_{i}(t)=\left\{v_{l}, v_{k}\right\}: v_{l}, v_{k} \in \Gamma_{i}^{1}(t) \wedge\left\{v_{l}, v_{k}\right\} \in E(t) \mid
$$

Now, we can define a very important concept, so called the local clustering coefficient
$C_{i}$ for a vertex $v_{i}$, which is given by the proportion of $N_{i}(t)$ divided by the number of edges that could possible exist between firstneighbourhood of a vertex $v_{i}$ (every neighbour of $v_{i}$ is connected to every other neighbour of $v_{i}$ ). Formally:

$$
C_{i}(t)=\left\{\begin{array}{cc}
\frac{2 N_{i}(t)}{k_{i}(t) \cdot\left(k_{i}(t)-1\right)}, & k_{i}(t)>1 \\
0, & k_{i}(t) \leq 1
\end{array}\right.
$$

The clustering coefficient $C$ for the whole network is define as the average of $C_{i}$ overall $v_{i} \in V$ i.e.:

$$
C(t)=\frac{1}{|V(t)|} \sum_{v_{i} \in V(t)} C_{i}(t)
$$

The degree distribution $P(k, t)$ of a network is defined as the fraction of nodes in the network with degree $k$. Formally:

$$
P(k, t)=\frac{\left|V_{k}(t)\right|}{|V(t)|}
$$

where: $\left|V_{k}(t)\right|$ is the number of nodes with degree $k ;|V(t)|$ is the total number of nodes.

\section{Models of Complex Networks}

Intuitively, communication in the network is very efficient when each node is connected to each other. On the other hand, it causes that a large number of that connections is required what is often forbidden (variety of reasons may be raised) or simply too expensive. All in all, in this particular case there are two different and contradictory criteria an efficiency and a cost.

Most of the real-world networks, so called Complex Networks [7], [8] despite they are very rare (have small number of connections), are found to have: small average path length, relatively small diameter, high clustering coefficient, and degree distributions that approximately follow a power law, i.e. $P(k, t) \sim k^{-\gamma}$, where $\gamma$ is a constant. These features whose origin are nowadays discovered indeed affect communication characteristic within networks.

It is worth to mention that algorithms, which generate Complex Networks, are used in CART (on various level: city, state, country) to 
propose the right topology of road infrastructure, in order to:

- Maximize the efficiency of communication between the network nodes (cities, intersections);

- Minimize the number of necessary connections (roads) between the nodes;

- Additionally these algorithms maximize the resistance of the network to changing environment conditions (accident, closed road);

One of the most popular Complex Networks model is Small World [9]. This model is a result of simple observation that real networks have topology somewhere between regular and random one (Figure 1). The parameter $p$ is used to introduce randomness (edge "rewiring") in initially regular graph. Small World network is a type of network in which despite the fact that most nodes are not neighbors of one another (the graph is rare) and clustering coefficient is high, the average path length is low.

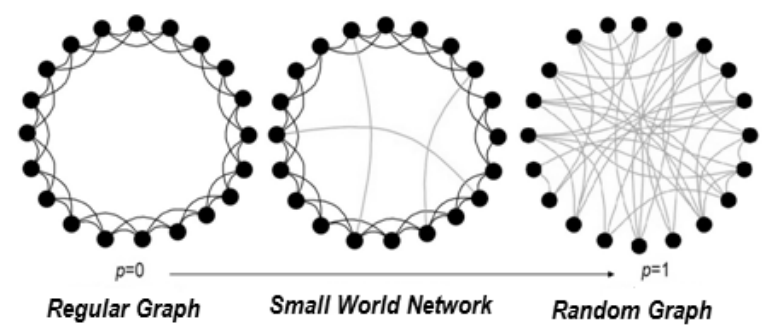

Fig. 1. The idea of Small World network models

The Scale Free network [1] is yet another model of Complex Networks as a result of two main assumptions: constant growth and preferential attachment. It explains why the distribution of nodes degree is describe by a power law.

The process of network generation is quite simple. The network grows gradually, and when a new node is added, it creates links (edges) to the existing nodes with probability proportional to their connectivity. In consequence nodes with very high degree appears (so called hubs or super-spreaders), which are very important for communication in networks (Figure 2).

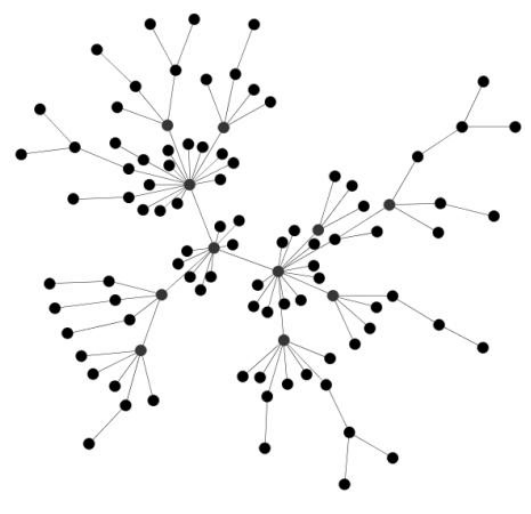

Fig. 2. The idea of Scale Free network model

\section{Measures of nodes importance}

The most fundamental and frequently used measures of network structure are centrality measures [3]. The central vertices in networks are of particular interest because they might play the key role within network (in particular road infrastructure). Centrality measures addresses the question of "What is the most important or central node in a given network?". Of course no single measure is suited for all applications. They are based on different formulas and should be used depending on a given context.

\section{Degree centrality}

The degree centrality (Figure 3) is the simplest and most intuitive centrality measure. It gives the highest rank to the node that has the highest degree (the largest neighbourhood).

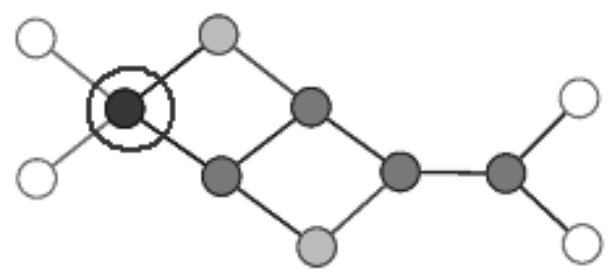

Fig. 3. The importance of nodes according to the degree centrality

$$
d c_{i}(t)=\frac{k_{i}(t)}{|V(t)|-1}
$$

\section{Betweenness/Load Centrality}

The betweenness centrality, sometimes called the load centrality (Figure 4), is defined as the percent of shortest paths connecting any two vertices that pass through the considered vertex. If $p_{l, i, k}(t)$ is the set of all shortest paths between 
vertices $v_{l}$ and $v_{k}$ passing through vertex $v_{i}$ and $p_{l, k}(t)$ is the set of all shortest paths between vertices $v_{l}$ and $v_{k}$ then:

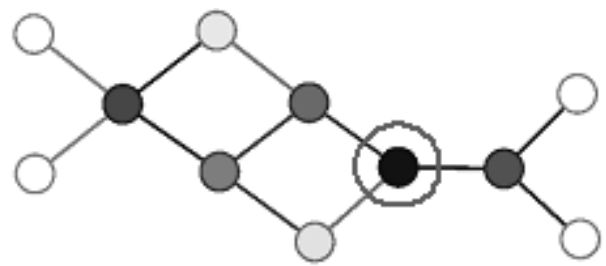

Fig. 4. The importance of nodes according to the betweenness/load centrality

$$
b c_{i}(t)=\frac{\sum_{l<k} \frac{p_{l, i, k}(t)}{p_{l, k}(t)}}{(|V(t)|-2)(|V(t)|-1)}
$$

Degree and betweenness centrality measures assess the load of individual nodes. Thus, outcome of applied measure on given nodes indicates where to build e.g. ring roads, detours, or petrol stations.

\section{Radius centrality}

The radius centrality (Figure 5) chooses the vertex with the smallest value of the longest of the shortest path starting in each vertex. So if we need to find the most influential node for the most remote nodes it is quite natural and easy to use this measure:

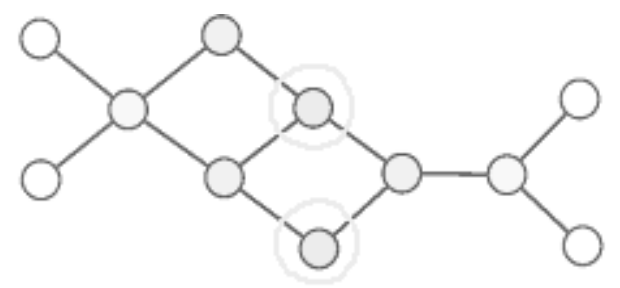

Fig. 5. The importance of nodes according to the radius centrality

$$
r c_{i}(t)=\frac{1}{\max _{v_{j} \in V(t)} d_{i j}(t)}
$$

It indicates where is the best location for emergency services like fire brigade, police, or ambulance service.

\section{Closeness centrality}

According to the closeness centrality (Figure 6) a given node is the more central, the closer it is to other nodes of a given network.

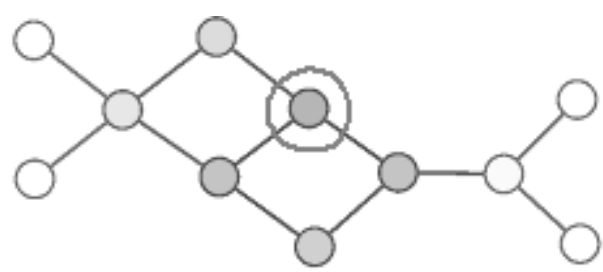

Fig. 6. The importance of nodes according to the closeness centrality

This measure lets us indicate which of any two nodes requires fewer steps to "communicate" with another node:

$$
c c_{i}(t)=\frac{|V(t)|-1}{\sum_{v_{j} \in V(t)} d_{i j}(t)}
$$

Thus, values on network nodes indicate where to build e.g. shipping centres, facilities or supermarkets.

\section{Eigenvector Centrality}

The eigenvector centrality (Figure 7) acknowledges that not all connections are equal.

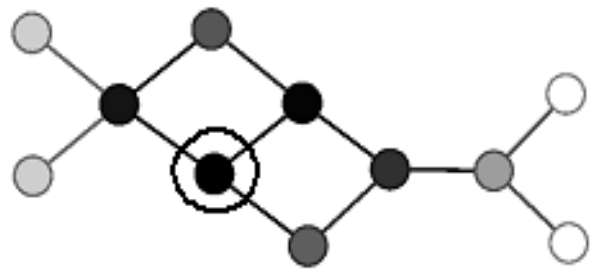

Fig. 7. The importance of nodes according to the eigenvector centrality

If we denote the centrality of vertex $v_{i}$ by $e c_{i}$ then we initiate this effect by making $e c_{i}$ proportional to the centralities of $v_{i}$ 's first neighbours:

$$
e c_{i}(t)=\frac{1}{\lambda} \sum_{j=1}^{|V(t)|} a_{i j}(t) \cdot e c_{j}(t)
$$

Eigenvector centrality measure assess the road hierarchy. Thus, values on nodes indicate where to build a new road for local residents directly to a highway. 


\section{The CART System}

CART stands for Creative Application to Remedy Traffic. The system can be classified as a DSS (Decision Support System). It was designed and developed by students of Military University of Technology in Warsaw during Imagine Cup 2011 [10]. The motivation for building CART was one of Millennium Goals defined by United Nations - "Ensure environmental sustainability" [11].

CART takes advantages of experiences acquired thanks to CARE and CARE2 systems [4], [5] which were developed during Imagine Cup 2009 and 2010 competitions. The system was awarded and got to the TOP 10 innovative projects in Polish Imagine Cup finals.

CART has been developed especially for government and authorities who make decisions about road infrastructure in agglomerations. Businesses can also benefit from using it by pointing the best place suitable e.g. for patrol stations or supermarkets. The third target group of users are drivers, who can apply it to plan a trip using statistical traffic data or to get information about detours in real time while being in a car.

The main reason for making this software is to improve road infrastructure which will reduce time spent in traffic jams. It transforms into lower costs for drivers (in particular lower costs of petrol and reducing the opportunity cost of time spent in a jam). One of the biggest advantages is protection of the environment. If we reduce traffic jams, there should be less smog. That's why overall health of the society in cities should be better.

\section{CART Functionalities}

The main screen of CART which shows list of functionalities is depicted in Figure 8.

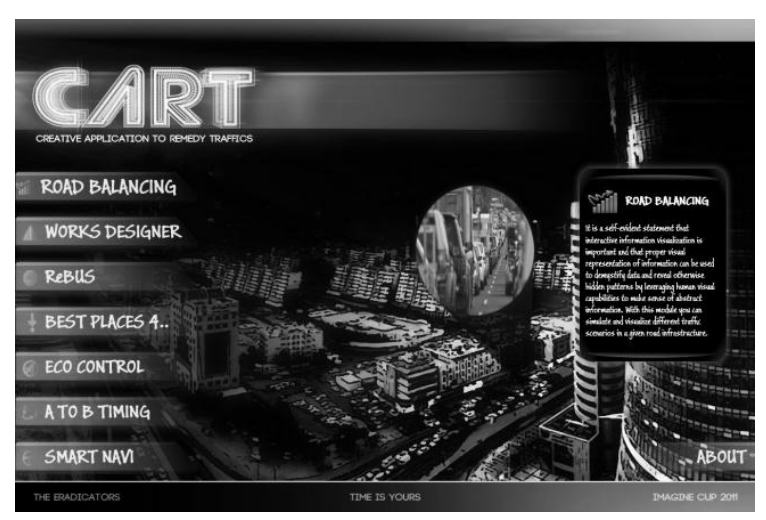

Fig. 8. CART functionalities

\section{Road balancing}

The objectives which concern unloading traffic jams can be achieved by implementing changes in the road infrastructure. CART can help decision makers to optimize topology of the roads to get a greater road capacity (see Figure 9). This is achieved by utilizing Complex Network theory, in particular centrality measures and computer simulation. CART generates hints where and how a change should be done. This can result in changing existing roads, adding new, changing directions of a lane or even closing or making a road one-way only. What's more, decision makers using computer simulation can see and understand how the change will affect whole infrastructure e.g. of a city or a particular area. The simulation engine is able to use historical data about traffic or even generate traffic with different distributions. All in all, thanks to CART, it is possible to compare road infrastructure efficiency before and after almost any kind of changes. The process of generating proposals for changes and simulation running can be or even should be repeated as many time as decision makers wish.

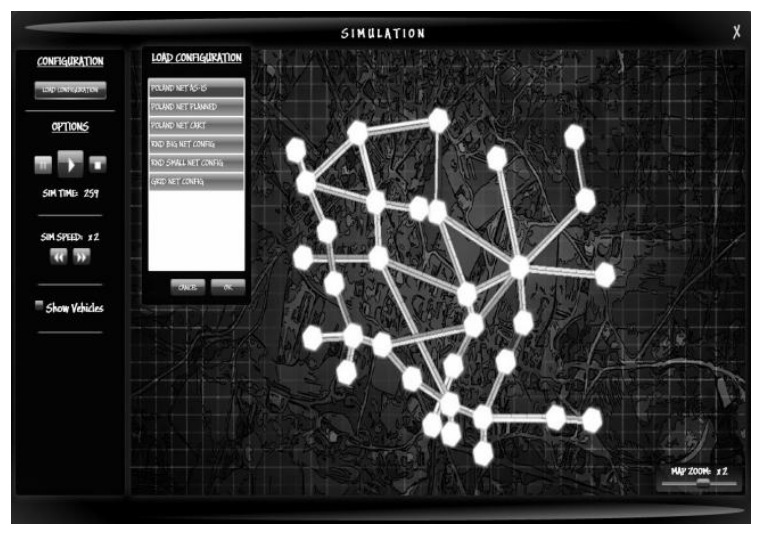

Fig. 9. Road overload simulation

\section{Works designer}

This module is dedicated strictly for authorities who are responsible for designing, building roads and making detours. Whether there is a flood (reverberating on roads), surface repair (which makes impossible to drive through) or mass party (procession on the road), we are facing a situation with a closed (blocked) road. Thanks to this editor (see Figure 10), authorities can make changes to the infrastructure - in a manner which is commensurate to the situation. Then by taking advantage of the centrality measures, CART can compute by which points the detour should be conducted. Of course users may change to the proposal and simulate traffic. In this case they can see how 
the changes made to the infrastructure have influence to traffic in wider sense.
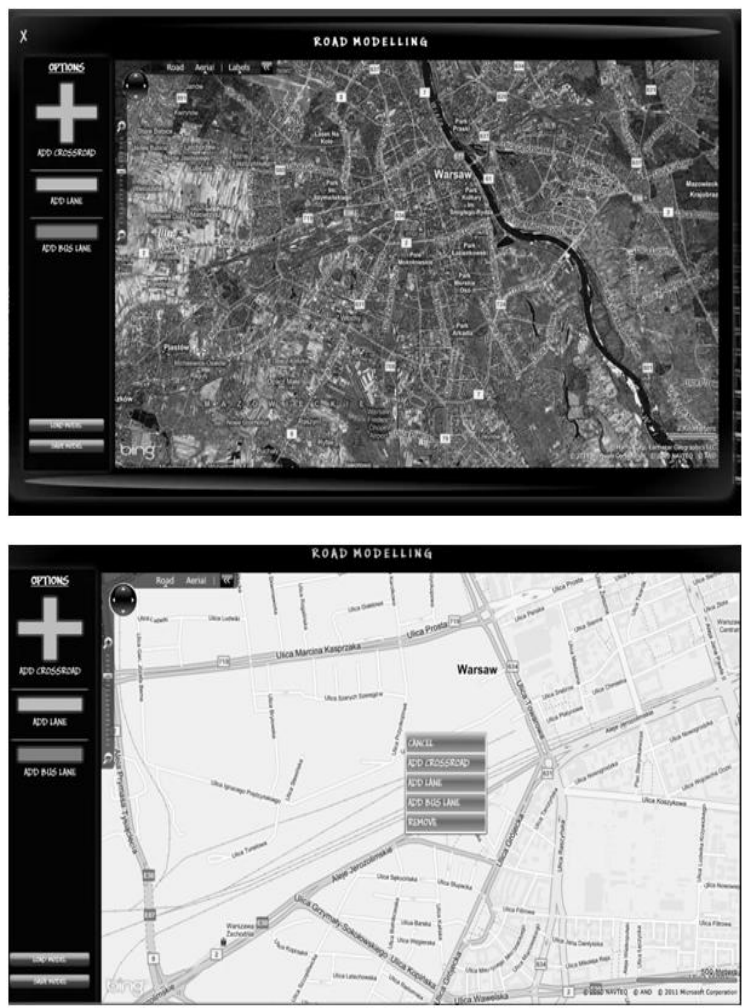

Fig. 10. Road infrastructure optimization

\section{ReBUS}

The next module is responsible for analysis of bus lanes within an agglomeration. As traffic jam gets heavier authorities tend to close particular lanes for cars and mark them as BUS lanes. Although the intentions are good, this approach not always works. In special cases such method can paralyze the city. CART can simulate and visualize it and in consequence helps decision makers to make the right decisions.

\section{Best places "4"}

The authorities and businesses would use this module to discover where to put a Park and Ride facilities, build a patrol station, a shopping centre or even emergency services. The outcome can tell where would be the best place for these.

\section{ECO Control}

This module is environment-oriented. Thanks to advanced simulation and the urban terrain maps we can plan road infrastructure that will bring the lowest noise and pollution levels both humans and animals. The efforts of this simulation can convert into planning trees or building soundproofing walls near the most exhausting fumes zones (see Figure 11 and 12).
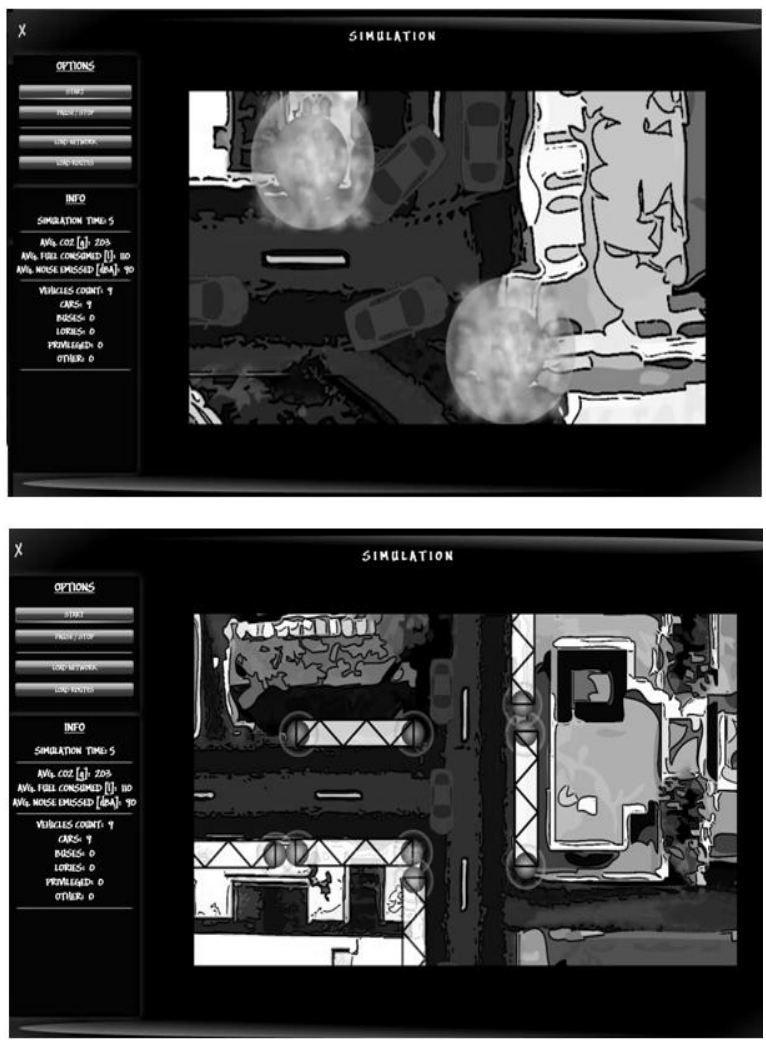

Fig. 11. Environment and noise control

\section{A to B timing}

Thanks to this module we can tell you how much time will you spend in a car during a trip from place A to place B during different times of the day, with given simulation parameters. On the one hand, simulation takes under consideration parameters like time of the day, holidays and facilities (around the trip path and their load probability) and even current traffic data from cars with installed GPS device. On

the other hand, statistical parameters are also taken under consideration. So the simulation gives great amount of probability how long the trip can last.

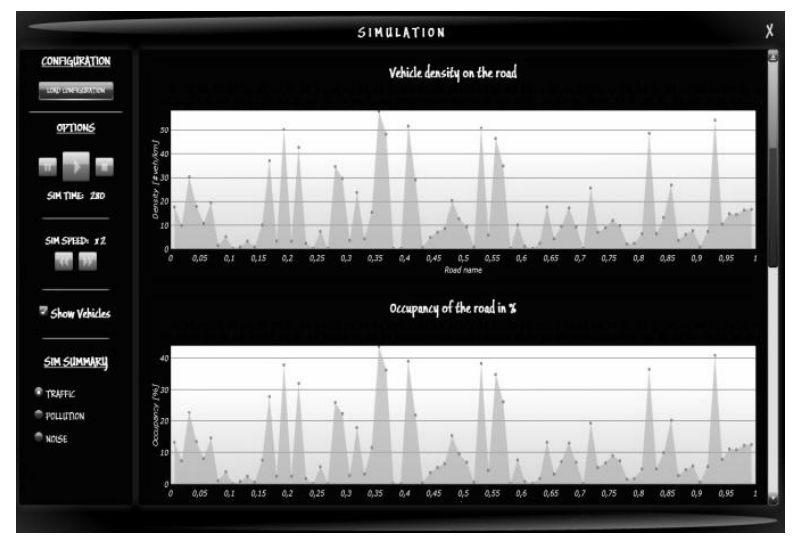

Fig. 12. Environment and noise control simulation - reports 


\section{Smart NAVI}

Smart NAVI is nothing like standard navigations. Thanks to it we can represent current road traffic state and lead a driver through the best road with minimum traffic.

\section{CART Architecture and Technologies}

CART is based on the client-server architecture. Within the server side there is SOA (Service Oriented Architecture) [12] applied. Furthermore the architecture is based on cloud computing paradigm - Windows AZURE [13]. This architecture is depicted in Figure 13.

The client side is divided into two separate user interfaces. The main interface is web based, and it's responsible for interaction with a user and displaying results of executed services. The other - dedicated for mobile devices interface is a lightweight GUI designed to consume only few resources. Its main aim is to display smartGPS path and send data about current traffic (based on global positioning system coordinates and velocity).

Server side is divided in three logical layers: services, integration and database. The first one consists of dedicated services, which are the backbone of the application and constitute the main business logic. The integration layer is the mediator between the services within, as well as the 'outside world' via WCF (Windows Communication Foundation) [14] and Azure Queues. In this layer the SUMO (Simulation of Urban MObility) [15] component resides. It is the heart of the system. This component is responsible for all the simulation in CART. Last but not least there is the database layer which consists of AZURE: SQL and Blobs. It is responsible for data storage and retrieval. Thanks to cloud computing the architecture is reliable, efficient and able to scale out (horizontally). Additionally the security is ensured by Azure storage redundancy.

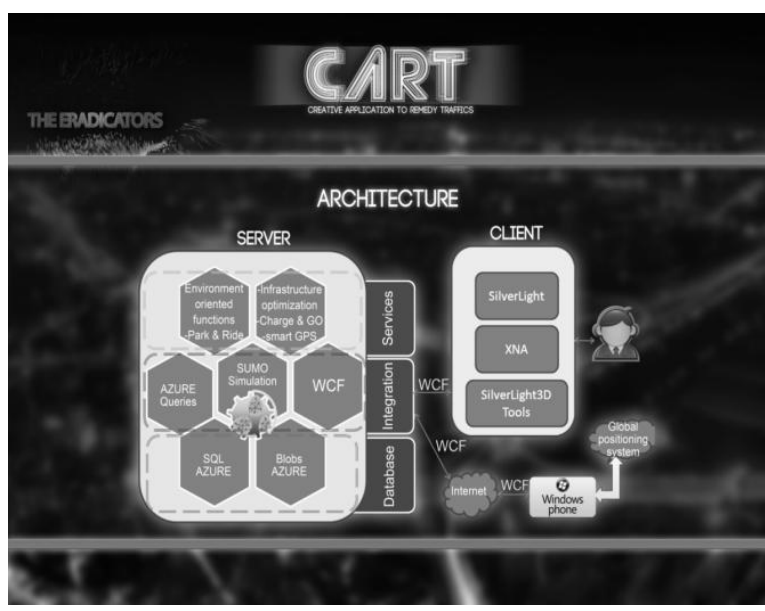

Fig. 13. CART architecture

\section{Summary}

CART is intended for the organizations (like authorities) responsible for the planning of road infrastructure and traffic management, as well as businesses and ordinary people. The first group of users will be able to assess the suitability of a proposed modification of road infrastructure (e.g. traffic light arrangement, detours, location of patrol stations, parking lots, Park \& Ride). CART can have enormous effect in struggle with smog and noise factors. The second group of users can take advantage of CART in planning best locations for their businesses (e.g. patrol stations, car wash, supermarkets). The third group of users, drivers and people who want to plan their trip can use the A to B timing and Smart Navi to estimate their trip destination time.

The CART software has enormous practical potential in big agglomerations, in particular Warsaw. CART will help to optimize road infrastructure and in consequence unload the traffic jams and congestions as well as it will improve environmental conditions in cities around the globe.

\section{Bibliography}

[1] Barabási A.L., Albert R., "Emergency of Scaling in Random Networks", Science, Vol. 286, 509-512 (1999).

[2] Bartosiak C., Kasprzyk R., Najgebauer A., "The graph and network theory as a tool to model and simulate the dynamics of infectious diseases", Bio-Algorithms and Med-Systems, Vol. 9, Issue 1, 17-28 (2013).

[3] Wuchty S., Stadler P.F., "Centers of complex networks", Journal of Theoretical Biology, 222, 45-53 (2003). 
[4] Kasprzyk R., Lipiński B., Wilkos K., Wilkos M., Bartosiak C., "CARE - Creative Application to Remedy Epidemics", Biuletyn Instytutu Systemów Informatycznych, $\mathrm{Nr}$ 3, 45-52 (2009).

[5] Kasprzyk R., "The vaccination against epidemic spreading in complex networks", Biuletyn Instytutu Systemów Informatycznych, $\mathrm{Nr} 3$, 39-43 (2009).

[6] Kasprzyk R., "Diffusion in Networks", Journal of Telecommunications and Information Technology, $\mathrm{Nr} 2 / 2012$, 99-106 (2012).

[7] Newman M.E.J., "The structure and function of complex networks", SIMA Review, Vol. 45(2), 167-256 (2003).

[8] Strogatz S.H., "Exploring complex networks", Nature, Vol. 410, 268-276 (2001).

[9] Watts D.J., Strogatz S.H., "Collective dynamics of 'small-world' networks", Nature, Vol. 393, 440-442 (1998).

[10] http://www.imaginecup.com/

[11] http://www.unic.un.org.pl/cele.php

[12] http://www.service-architecture.com/ articles/web-services/service-oriented_ architecture_soa_definition.html

[13] http://www.microsoft.com/windowsazure/

[14] http://msdn.microsoft.com/en-us/library/ ms731082(v=vs.110).aspx

[15] http://sumo-sim.org/

\title{
CART - CREATIVE APPLICATION TO REMEDY TRAFFIC
}

\author{
R. KASPRZYK, K. SZKÓŁKA, T. POPŁAWSKI, M. PYŻANOWSKI, P. GIĘTKOWSKI
}

CART to symulacyjny system wspomagania podejmowania decyzji, którego celem jest poprawa przepustowości infrastruktury transportowej i ,,płynności” ruchu pojazdów w aglomeracjach miejskich. Dzięki innowacyjnym rozwiązaniom łączącym nowoczesne technologie informatyczne oraz osiągnięcia z dziedziny teorii grafów i sieci, system jest w stanie przyczynić się do poprawy obecnych warunków na drogach. System przeznaczony jest zarówno dla organizacji odpowiadających za zarządzanie ruchem w mieście, jak i dla użytkowników dróg. Pierwsza grupa poprzez analizę wyników symulacji zmodyfikowanej infrastruktury dróg może w sposób świadomy i efektywny ocenić przydatność rozwiązania dla miasta (rozmieszczenie sygnalizacji świetlnej, budowa stacji benzynowych/parkingów, modyfikacja/rozbudowa samej sieci połączeń drogowych). Druga grupa dzięki wykorzystaniu inteligentnego systemu wspomagania organizacji ruchu będzie mogła płynniej przemieszczać się po mieście.

Słowa kluczowe: sieci złożone, miary centralności, infrastruktura drogowa, optymalizacja, symulacja. 